\title{
1. Public research enterprises: The changing landscape
}

\subsection{PUBLIC FUNDING TRENDS AND RESEARCHER INCENTIVES}

A major driver of US economic development since the Second World War has been productivity growth. The university research system has played an essential role in fostering productivity growth by consistently generating outputs with public good characteristics that have been easily reproducible and thus have not lent themselves to private market development and appropriation. Despite the success of this system, the scientific research establishment has come under increasing scrutiny and federal and state research funding (in real dollars) has been on a downward trend since the 1980s (Just \& Rausser, 1993). More importantly, the scientific research establishment has received a declining share of the federal budget. Scientific research and development (R\&D) received nearly 12 percent of the federal budget in the mid-1960s, but this share has fallen below 4 percent in recent years (Figure 1.1). This decline in federal public research funding has coincided with a slowdown in productivity growth, which has slowed since the 2008 Financial Crisis (Fernald \& Wang, 2015). The composition of federal funding reflects similar patterns with the exception of National Institutes of Health (NIH) biomedical research which continues to receive support from federal legislative bodies (Figure 1.2).

State and local government research funding has declined along with federal funding. Historically, many states have provided a significant share of public research university revenue. From 2002 to 2010, state support for public research universities fell 10 percent, while enrollment increased by 8 percent (NSF, 2012). This meant that state support per student fell by an average of 20 percent over that period (NSF, 2012). Though some of these funding cuts were driven by the Great Recession and funding rebounded somewhat after 2010, no state has restored funding to its pre-recession levels as of 2014 (Center on Budget and Policy Priorities, 2014). Over the six years following the Great Recession, the average state cut funding per student by 23 percent, in line with pre-recession trends (Center on Budget and Policy Priorities, 2014). 


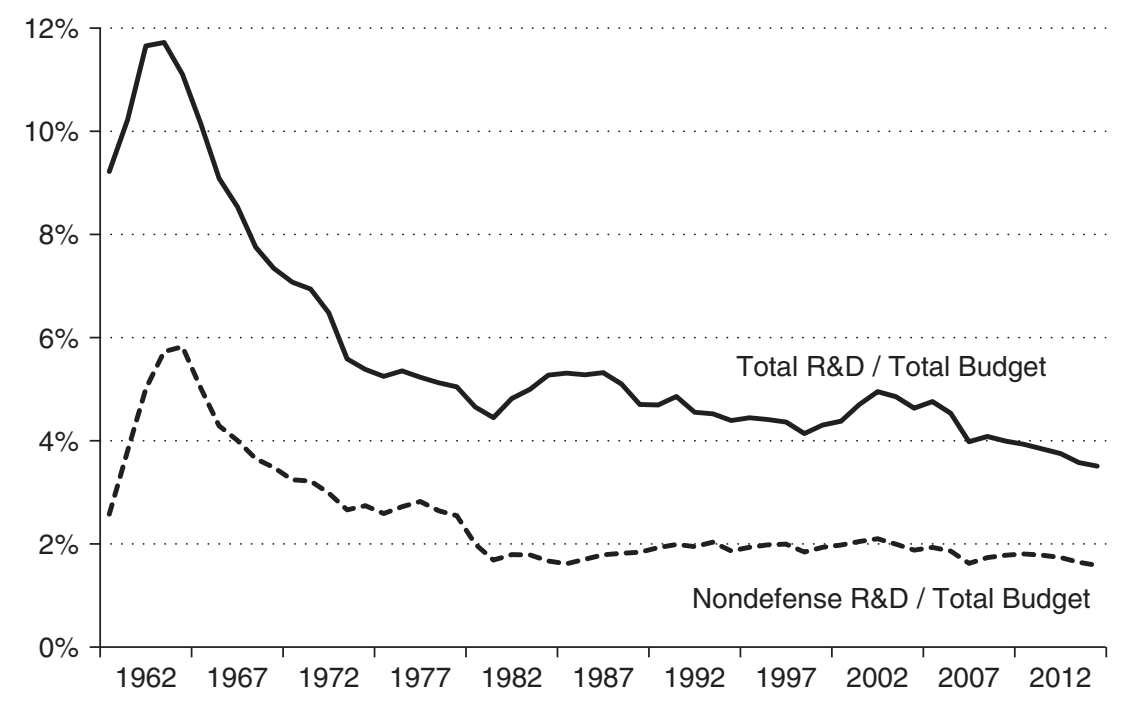

Source: American Association for the Advancement of Science.

\section{Figure 1.1 Public sector R\&D funding}

As the public sector contributions to university research budgets have declined, the need to seek out alternative sources of funding has become increasingly imperative. R\&D funding from the private sector has steadily grown over the last 50 years, and now accounts for over 70 percent of national ${ }^{1} \mathrm{R} \& \mathrm{D}$ budgets (Figure 1.3). In effect, the federal government and private enterprise have essentially switched roles in terms of the execution of R\&D funding. Private industry frequently offers a viable alternative, not only because of its financial resources but because of the dramatic synergies of knowledge that arise from successful alliances. Unsurprisingly, many universities have responded to the changing budgetary environment by readily accepting funding from the private sector. Nevertheless, even though the proportion of privately funded research has increased significantly, it remains a small portion of total funding for university- and college-led research (Figure 1.4).

In most universities, researchers have been encouraged to replace federal funding with external research grants, many of which are sourced from private commercial interests. As a consequence, many researchers' marginal research time and the generation of ideas are focused increasingly on specific private interests. As a result, private firms are leveraging their $\mathrm{R} \& \mathrm{D}$ funds to redirect a larger share of 


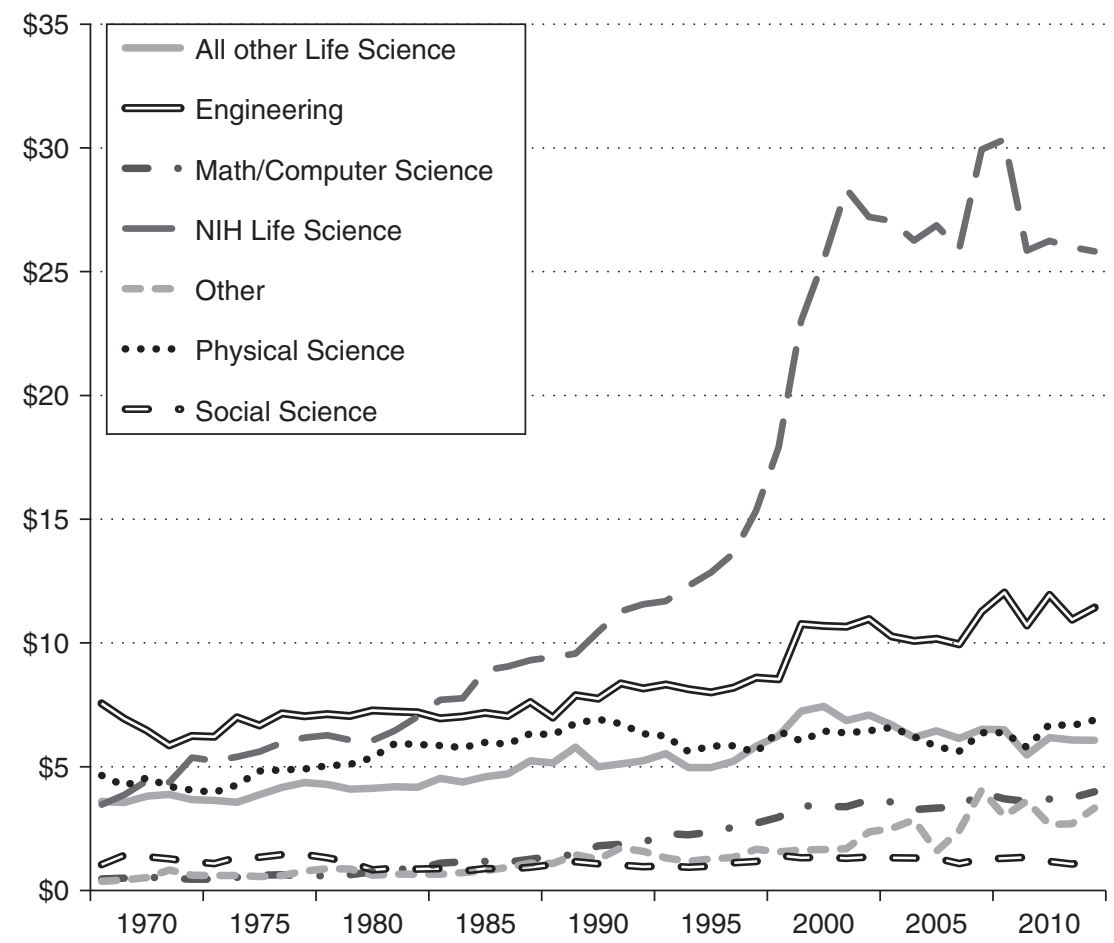

Source: American Association for the Advancement of Science.

\section{Figure 1.2 Funding by discipline}

universities' research efforts, gaining increasing influence over the public research agenda.

The changing landscape exists not only for universities but also for public sector research conducted at governmental agencies. For example, the President's Council of Advisors on Science and Technology (2012) recommended that the US Department of Agriculture research portfolio be rebalanced by the creation of innovation institutes funded through public-private partnerships (PPPs). ${ }^{2}$ The justification, in part, for this recommendation was to overcome "congressional constraints" on research funding budgets sourced by the federal government. 


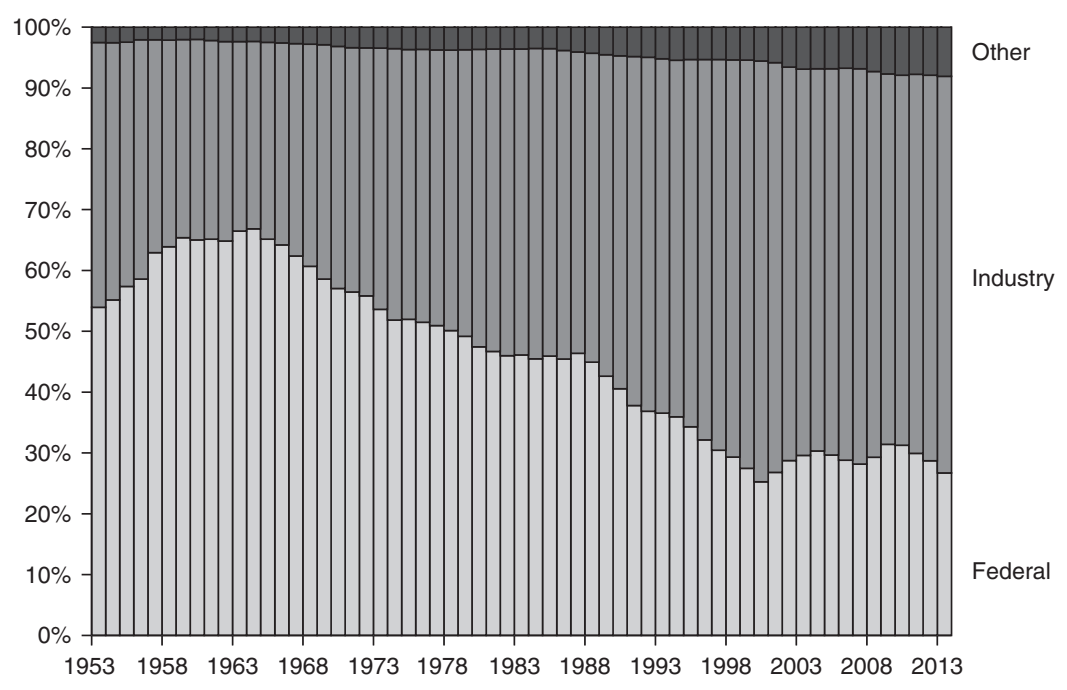

Source: American Association for the Advancement of Science.

\section{Figure 1.3 Trends in research funding}

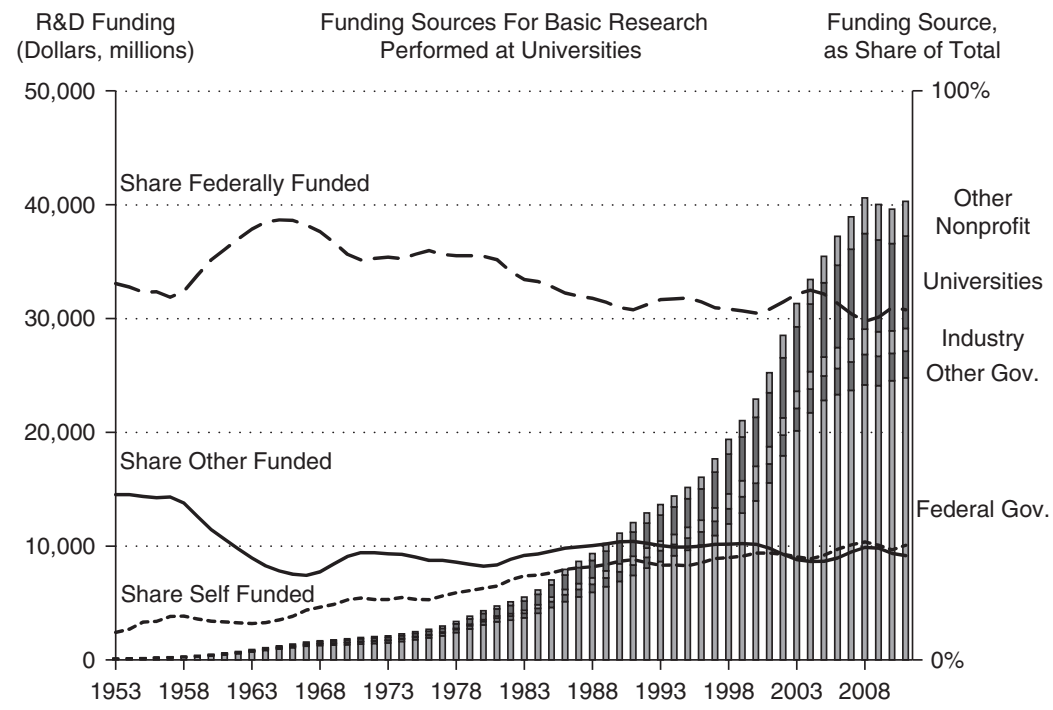

Source: National Science Foundation.

Figure 1.4 Basic research funding trends 


\subsection{INTELLECTUAL PROPERTY LAW AND RESEARCHER INCENTIVES}

Along with changes to the research funding landscape, changes to IP (intellectual property) law have created new incentives for researchers to pursue innovations that have commercial value. Prior to 1980, the government was assigned property rights for major discoveries resulting from publicly funded research at universities. This structure had a chilling effect on university researchers' attempts to commercialize their research. Innovation was also hampered because the government did not typically allow exclusive rights to these discoveries, but would only grant non-exclusive licenses to firms interested in commercializing the research. Firms were reluctant to pursue non-exclusive licenses because successful commercialization would draw competitors that could simply incur a government licensing fee and gain access to the same IP. Given the incentive structure, it is not surprising that only 5 percent of patents owned by the federal government were licensed for development by the private sector (Schacht, 2009).

As the US economy stalled in the late 1970s, policymakers searched for ways to increase the use of academic research discoveries by the private sector. Efforts to increase the commercialization of government funded research focused on changing the assignment of property rights from the government to the research institution. Critics were concerned that this reform would allow private companies the lion's share of new discoveries, where the burden of financing the underlying research is borne by the US taxpayer (Stevens, 2004). Proponents countered that, without allowing research institutions to capture some of the benefit associated with their research, discoveries would continue to go undeveloped and a significant source of economic growth would go untapped. As a result of public discourse, legislation emerged from the US Senate in the form of the BayhDole Act. This act gained support by only granting patent rights from federally funded research to universities and small businesses, not large private government contractors.

The passage of the Bayh-Dole Act in 1980 dramatically altered the incentives landscape by structurally changing IP rights and royalty distributions within a university (Washburn, 2005). Under the Act, IP rights are assigned to the universities where the research takes place, even if the research is federally funded, and it requires that universities share any license revenues with the inventors. This allocation of the royalty stream gives university researchers incentives to select areas of research that are likely to result in commercially valuable innovations. In essence, by directing their research toward private sector interests and commercially applicable innovations, university researchers can 
increase the likelihood of receiving remuneration. Researchers commonly receive one-third of licensing fees with the remainder split evenly between the university and other university units (in many instances, the academic department where the researcher resides), though some universities use a sliding scale to split net revenue with researchers (Jensen $\&$ Thursby, 2001). There is much variation by university; for example, researchers at Oxford retain 16 percent of net revenues above $£ 720,000$ (Isis Innovation, 2003). University of Washington researchers receive 27 percent of net revenue (University of Washington, 2015) while Johns Hopkins University researchers receive 35 percent of net revenues in addition to the 15 percent of net revenues their personal lab receives (Johns Hopkins University, 2011).

IP law also incentivized researchers by expanding property rights for researchers over discoveries in the field of biotechnology. In 1980, the US Supreme Court ruled in Diamond v. Chakrabarty (US Diamond v. Chakrabarty, 1980) that researchers could patent the genetically modified organisms (GMOs) they create. This ruling helped revolutionize the biotechnology field. In the decades following the ruling, thousands of biotechnology companies were founded, which employed hundreds of thousands of people, and spent tens of billions of dollars on R\&D (Robinson \& Medlock, 2005). Research conducted in unversities has been crucial to the success of the biotechnology companies; many have been started by professors and most employ research professors as consultants (Zucker et al., 1998). These companies provide significant compensation for professors willing to conduct commercially valuable research.

The Bayh-Dole Act has had a dramatic and sustained effect on licensing by universities. According to surveys by the Association of University Technology Managers (AUTM), over 4,000 firms have been spun off from universities (AUTM, 2012). Licensing contributes an increasing share to university revenues, as average yearly license executions have nearly tripled from 1997 to 2013. And this growth has continued despite federal research funding declines. For example, in 2014, new commercial product licenses jumped 34 percent despite a 5 percent decline in federal research funding (AUTM, 2015). To illustrate how quickly the university research landscape has expanded its organizational structure, largely as a result of the Bayh-Dole Act, there were only 27 technology transfer offices (TTOs) at universities prior to the passage of the Bayh-Dole bill. The trajectory of TTOs began with 7 that were founded before 1960, which increased to 113 in 1979, 200 in 1990 and then more than quadrupled by the turn of the century.

The growth of technology firms near universities is another indicator of the impact of the Bayh-Dole Act. Research at Stanford University 
was one of the major engines of growth in Silicon Valley, discoveries at the Massachusetts Institute of Technology (MIT) and Harvard developed businesses along Route 128, and similar research discoveries in Austin, Texas and in the Research Triangle in North Carolina drove economic growth in nearby cities. The potential positive linkage effects on local business, utilizing the expertise of faculty as entrepreneurs or consultants, have resulted in many attempts to establish university research parks. One study on the formation of university startups within university research parks has been conducted by Link and Scott (2005). Their results suggest that, for biotechnology private firms, startups have a more pronounced presence than established firms while more established firms are more pronounced in parks or locations associated with elite research universities. These successes have spawned countless university imitators who have been said to experience "MIT Envy" (David, 1997). Universities have been quick to develop technology transfer offices, but the licensing revenue remains highly skewed toward the most successful research universities (AUTM, 2014).

Independent of the Bayh-Dole Act, it has always been in the financial interest of research universities to actively pursue monetization of their patents. The classic example is the University of Wisconsin Alumni Research Foundation. It is not a technology transfer institution, but instead frequently monetizes the value of the University of Wisconsin patent portfolio through litigation. This foundation has represented that it has over the years generated more than $\$ 1.5$ billion for the University of Wisconsin-Madison, an average contribution of $\$ 18$ million per year (Washington Post, 2015). In the most recent academic year, it generated more than $\$ 72$ million, amounting to 2.5 percent of the university's budget. Recently, this foundation filed a claim against Apple for infringement of a micro-processor patent that was developed through research at the University of Wisconsin-Madison and was awarded $\$ 862$ million in potential penalties by a lower court. In 2015 Carnegie Mellon University won a $\$ 1.1$ billion award from a jury against Marvell Technology Group, an amount that was later reduced on appeal from a lower court to \$278 million. According to Reuter's (Chung, 2015), universities are the source for filing 45-50 patent lawsuits every year. Aside from litigation, the Wisconsin Alumni Research Foundation holds the property rights for a number of patents; in 2013 alone, this foundation obtained the rights to 160 new patents. In terms of licensing revenues, the University of Wisconsin ranks 10th among US universities. "The University of California system, Northwestern University, Columbia University, New York University and Princeton University all made more than \$100 million in 2011 from patent licensing" (Washington Post, 2015). 


\subsection{THE CONFLICT BETWEEN PUBLIC AND PRIVATE RESEARCH INTERESTS}

As government funding has declined, the need to seek out new sources of funding has become increasingly imperative. Private industry frequently offers a viable alternative, not only because of deep financial resources, but also because of the dramatic synergies of knowledge that arise from successful alliances. These public-private research partnerships (PPRPs) offer university faculty funding for research that could not be conducted using government funds and charitable contributions alone. In a survey of natural resource faculty conducted by the University of California (UC), Berkeley (UC Berkeley, Academic Senate, Committee on Educational Policy, 1998), survey responses include the following observations from individual faculty: "If the state won't support departments appropriately, it is proper for the faculty to seek outside support"; "Do you really believe the state is going to fund Plant \& Microbial Biology's research? Please, get real"; "Arrangements like this may be the only way for Microbial Biology faculty to do cutting-edge research in a field currently dominated by industry"; "For those interested in research in the target area, this may be the only way to fund and perform pioneering research"; "Some sort of alliance of the type proposed is the only way academic research in genetic research has a chance in hell of staying at all up-to-date."

Opponents of these research partnerships suggest that private support for university research is a departure from the norm when, in fact, research universities have always been heavily dependent upon outside funding to sustain their research activities. A faculty member stated: "I believe that we have been subsidizing industry for too long and that [research partnerships] provide an opportunity to get something back ... . In my view [the research partnership] merely makes explicit what we have long done, removing the illusion and increasing the financial responsibility of industry for the benefits it receives."

Rather than viewing research partnerships as an act of "privatization," a number of faculty noted their huge potential to place in public service what are currently private technologies. One respondent stated: "[Research partnerships are] an excellent new opportunity for a public institution to be involved in this area, with public values of what previously had been exclusively private, to be realized."

Within the university, not all professors view PPRPs as an essential component of the university's research system, and PPRPs have remained controversial across research university campuses. Such controversies extend well beyond the potential non-alignment of interests among universities and private companies in the formation and implementation of research 
agreements. At a fundamental level, these controversies will always be with us. Their origin has a long history, emerging initially with the establishment of the National Science Foundation (NSF), to provide subsidized research grants to university researchers (see Chapter 2).

PPRP agreements, by their very nature, are attempts to pursue and capture commercial value. Many intellectual leaders strongly believe that the pendulum at research universities, as well as non-research universities, has swung too far in the direction of neoliberalism (Deresiewicz, 2014). Deresiewicz (2015) asserts, "Neoliberalism is an ideology that reduces all values to money values. The worth of a thing is the price of the thing" (p. 26). It is the humanities and liberal arts educators who are generally opposed to the establishment of PPRPs on research university campuses. PPRPs are another source of commercial values that biases the educational experience toward commercial interests. This may come at the cost of pursuing ideas for their own sake, not directed at some commercial value. What is lost is the capacity "to make autonomous choices - to determine your own beliefs, independent of parents, peers, and society. To live confidently, courageously, and hopefully" (Deresiewicz, 2015, p. 26). This perspective of the humanities and many social sciences, however, fails to realize that PPRPs are engaging only faculty researchers and graduate $\mathrm{PhD}$ students in agreements between private firms and universities. The graduate students have already selected their professional or commercial interests. There is no attempt or interest in engaging undergraduate students to pursue any commercial value associated with PPRPs. Accordingly, the opposition of humanities and liberal arts faculty to PPRPs, regardless of their contractual structure and implementation, is largely misplaced on neoliberalism grounds.

Still, humanities and social science faculty often express concerns over PPRPs invading their campuses. They contend that the conflicting interests of the public and private partner are irreconcilable. They fear that the private partner will have complete control over the research process and will curb academic freedom. Though these professors have a different view on research funding, since they do not typically have the research budgets of the hard sciences nor have they historically relied on private research funding, their fears about capture are well founded. There have been many poorly structured research partnerships where the public interest was not served.

An immediately recognizable example of a poorly structured research partnership is the Boots-University of California, San Francisco (UCSF) partnership. In 1995, Boots Co., a British pharmaceutical company and drugstores chain, spent $\$ 250,000$ to sponsor a study at UCSF investigating the bioequivalency of their drug, Synthroid, and three generics. In the 
contract, Boots Co. retained the contractual right to approve or disapprove publication of the study (a clause that was in fact against UCSF researcher policy). If they were found to be bioequivalent, Boots Co. would be expected to lose $\$ 600$ million in business per year. If Synthroid was judged to be biochemically unique, Boots Co. would maintain monopoly power and a pharmaceutical division valued at $\$ 1.4$ billion.

The study, led by Dr. Betty Dong of UCSF, found the four drugs to be bioequivalent. Since this was an unfavorable outcome for Boots Co., the company attempted to discredit the study. After review, Boots Co.'s criticisms were deemed to be unfounded and the study was ready to be published. However, Boots Co. threatened a costly and drawn out legal battle based upon the terms of the contract. Ultimately, the study was not published.

The experience of the UCSF researchers does not appear to be an isolated incident. Lexchin et al. (2003) reviewed 30 studies, which analyzed over one thousand clinical trials, on the effect of industry sponsorship of academic pharmaceutical research. The authors found that research funded by the pharmaceutical industry is more likely to produce results supportive of industry than research funded by non-industry sources. This statistically significant finding is robust across medical fields and over time. The authors also find that industry-supported research is less likely to be published in peer-reviewed journals, which appears to indicate a level of discipline-wide wariness of research that supports the claims of its funders. Surveys have also found that 20 percent of university research scientists admitted to delaying the publication of research to protect proprietary data (Blumenthal et al., 1997). This distrust and data withholding threatens to erode the foundations and core culture upon which many university research systems were founded.

The systemic bias in the pharmaceutical industry funded by the private sector validates the concerns of opponents of PPRPs. Academic integrity can be compromised and public resources can be captured when partnerships do not provide contractual protections for the public partner. Despite this danger, the question is not whether universities must deal with the outside world, but how effectively they will do so. Industry or private sector funding for academic research continues to replace government funds. This book provides a framework for optimizing the benefit to the public sector, especially research universities.

The task of forming research relationships is complex and delicate. Many lessons have been learned as public criticism and scrutiny of PPRPs has become increasingly intense (Press \& Washburn, 2000). Issues, such as conflict of public and private interests, setting research priorities (Rausser et al., 2008), ownership of, and access to, IP (e.g., issues of hold-up and 
blocking patents), and publication delays, fuel the current debate and very often present insurmountable obstacles to forming research partnerships.

At the center of the PPRP controversy is the absence of a framework for structuring research agreements, whether formal or implicit, and for assessing the inherent merit of such contracts. No optimal contract structure has emerged for these partnerships. Most work examining research partnerships tends to focus on the source of research funding, basic provisions of these agreements, associated problems and consequences, policy recommendations for fostering these relationships, or specific aspects of a particular type of agreement (The University-Industry Research Collaborative Initiative, 2001; President's Council of Advisors on Science and Technology, 2008a). Although this literature is useful, it sheds little light on how these agreements should be structured, in particular, to protect public research interests.

Yet the call continues for creative collaboration across companies, universities, governments, and nations (Hamm, 2009). On November 26, 2008, European Commission President Jose Manuel Barroso announced the European Economic Plan, which proposes the formation of three PPPs for the R\&D of energy-efficient buildings, new and sustainable manufacturing technologies for the "Factories of the Future," and the European Green Cars initiative (European Commission, 2008). The Lugar-Casey Global Food Security Act, introduced to the US Senate in February 2009, directs US assistance in developing agricultural technologies and specifically promotes public-private alliances. In September 2009, the Obama Administration released its "Strategy for American Innovation" calling for investing "more than three percent of GDP in public and private research and development" (National Economic Council, 2009).

This is a critical time to push beyond limited policies and develop a more comprehensive approach to structuring and evaluating PPRPs. We present a framework for analyzing the structure of contracts for PPRPs, recognizing that the essence of PPRPs is a set of "control rights" or embedded options. The four-stage framework, rooted in incomplete contracting and control rights theory, shows how control rights can be effectively identified, valued, and allotted between research partners.

\subsection{UNCERTAINTY AND CONFLICTING RESEARCH OBJECTIVES}

The Boots Co. case study illustrates two key obstacles that prevent successful research partnerships: conflicting objectives and uncertain outcomes. Private firms and public research institutions have divergent 
interests. Public research institutions allow researchers to establish their own research agenda and publicly disseminate the results of that research. Private firms typically give researchers less autonomy to create a research agenda, and do not release their findings publicly.

Opponents of PPRPs are convinced that corporations make inherently unsuitable partners because of their profit motivation. However, the history of innovation in the United States shows the obviously critical role that the potential for economic reward plays. Few important innovations could, or would, have occurred without the financial support of corporate backers. Such motivational incentives are embodied in the establishment of patent property rights in the United States. For example, as previously noted, the UC has been the beneficiary of this federally mandated IP system, adding to its coffers $\$ 118.2$ million of gross licensing revenue system-wide in the 2014 fiscal year alone (UC, 2014).

Despite the inherent conflict, successful research partnerships can be created in areas of mutual interest to both public and private researchers. To overcome the obstacle of conflicting objectives, the partners should create contracts that recognize the existence of conflict and clearly lay out a framework for resolving that conflict. There will always be conflict in the design and implementation of a research plan, and contracts must directly address these conflicts. If both partners can commit to resolving conflict in a mutually agreeable fashion, the likelihood of success is increased.

We use the field of collective choice to evaluate conflict in PPRPs. The lens of collective choice will help us frame the conflicts between the public and private partners that naturally arise in research partnerships. At their core, PPRP contracts should be designed to promote collective decision making that maximizes both private gains and social welfare. We investigate how collective choice can link governance structures and the distribution of political power in the design and implementation of PPRPs.

Partnerships are further complicated by the uncontrollable, unforecastable nature of scientific research. Research is an uncertain process; there is no way to guarantee a blockbuster discovery. The partnership's contract must directly address unanticipated events. There is no such thing as a complete contract. The contract must contain a set of implementable actions to be taken when events occur in the research partnership in unanticipated ways. The power granted in these situations is called the "control rights." These control rights must be allocated with constraints that protect academic freedom. Clearly assigning decision-making authority in unanticipated situations is necessary to prevent capture of public resources by the private partner.

Scotchmer (2004) has argued that PPRPs are particularly well suited for large science projects. For certain large projects, the public sector may face 
the problem of choosing the right investments, in particular those with a high probability of success. On the other hand, the private sector would typically have the expertise needed to screen likely successful projects, but can on occasion reap unappropriable social benefits, and thus will be unable to recover the cost of the research that they finance (Sheridan, 2007). This, of course, implies that asymmetric information may exist between the public and private partner with the latter having superior information about the probability of success, which in turn might allow the private firm or industry to strategically engage the public sector in subsidizing its privately profitable projects.

Once again, the question is not whether universities must deal with the outside world, but how effectively they will do so. In this respect, we provide a unique model for maximizing the benefit to the university and, therefore, to the public. This book is an operational document that gives specific guidance regarding the creation and execution of research partnerships. This guidance is based on both the successful and unsuccessful PPRPs of the last 30 years.

\subsubsection{Setting the Bargaining Space}

Typically, the university and its faculty wait passively until they receive Requests for Proposals (RFPs) from governmental agencies or private companies and then generate a response on the other party's terms. As a result they must live with, and never dictate, the critical terms of the relationship. By contrast, we recommend staking out a strategic advantage and inverting the typical process; universities can generate the RFP, allowing private companies with appropriate $R \& D$ interests to respond, guided by the university's principles and on the university's specific terms.

This approach was engineered by Berkeley in the late 1990s, when the College of Natural Resources (CNR) issued an RFP and the industrial candidates were asked to compete with each other to meet its conditions. The principles established by the CNR included capturing consistency between the research objectives of the faculty and the private research goals and established intellectual capital of the partner; maintaining absolute faculty freedom and autonomy; obtaining otherwise cost-prohibitive technological resources for the faculty; and maximizing discretionary resources for infrastructure and graduate programs.

\subsubsection{Preserving Academic Freedom}

Universities should be wary of ceding control by placing private employees on university committees. However, it may be appropriate to involve the 
private partner in allocating funding among research projects. Naturally, the private partner will be interested in allocating portions of the research funding it contributes, but it would be inappropriate to cede control of the process entirely. In a major case study, research funds were allocated by a board which was comprised of three elected faculty members from the university faculty and two private firm officials. The inclusion of these private company officials was requested by the participating faculty; it was not a condition imposed (or for that matter, requested) by the private partner.

No faculty member should be required to sign a confidentiality agreement, or, for that matter, participate in any fashion in the research alliance; involvement must be strictly voluntary. Confidentiality agreements are absolutely standard for those who choose to conduct research with private industry but, in a preferred alliance, the participating faculty are free to choose whether to commit to such confidentiality.

\subsubsection{Private Sector Presence on Campus}

Another question regards company scientists being present on the campus as adjunct faculty. No special privileges should be extended to private sector employees. Contracts should include a provision that states clearly that (like everyone else) the private partner's employees are subject to standard university employment policies. This means that any particular adjunct appointment must satisfy the university's personnel and employment policies as a process separate from the PPRP.

\subsubsection{Dealing With the Inevitable Controversy}

Certainly, there are conflicting views regarding partnerships with the private sector, and the differing perspectives of all stakeholders should be thoughtfully considered. Every university should carefully monitor and study the results of research partnerships so that they may sharpen their best practices for collaborating with the outside world, rather than turning their back on them in fear. It should be the mission of university administrators and faculty to foster diverse (and often conflicting) avenues of investigation and search for points of possible integration. Along the way there will inevitably be disagreement, but contention cannot be allowed to block the innovation, risk taking, and academic independence which characterize the university's culture. If a minority of students and faculty are allowed to control the research agenda for the university, fewer outstanding professors will be hired, fewer of the best students will enroll, and ultimately, the university will attract less public support. The public interest is best served when divergent approaches are required to compete on the level 
playing field of science in lieu of the rough terrain of politics. Rather than yielding to fears about PPRPs, research partnerships should ultimately be measured by their results.

\subsection{OUTLINE OF BOOK CHAPTERS}

We begin our examination of PPRPs in Chapter 2 by reviewing two competing paradigms for modeling the scientific research process: the linear decomposition and the non-linear, chaotic, feedback research paradigms. The discussion of research paradigms is not simply an academic exercise, as each paradigm has important implications for universities contemplating PPRPs. We present empirical evidence on the distinction between public good and private good research in Chapter 3 while in Chapter 4 we explore whether private funding crowds-in or crowds-out public good research in a non-linear, chaotic, feedback paradigm. We pivot from these abstract models to knowledge creation and the R\&D process in Chapter 5. Both the theoretical and empirical literatures on the knowledge generation process have important implications for PPRPs. In Chapter 6 we turn to real-world examples, assessing a few notable case studies. Over the last 30 years, the private sector has funneled hundreds of millions of dollars into university research through PPRPs, and we review the basic terms and conditions of such contractual commitments. We also present guidelines universities have developed to manage these partnerships and assess consistency across these guidelines.

In Chapter 7 we advance a collective choice framework to interpret the selection and implementation of PPRPs in the face of conflicts between private self-interest versus the public interest. We isolate the political, economic, and ideological forces that emerge in the strategic interactions among the partners. This allows us to formally demonstrate the crucial role that the assignment of authority, control, or decision rights plays in the collective choice arising from PPRPs. Based on this core result, in Chapter 8 we present the key insights from the finance literature on incomplete contracts and control premiums, or decision rights, in the generation of private and public goods. In Chapter 9 we extend this analysis to impure goods that are generated from a PPRP. In Chapter 10 we develop a four-stage process for forming and managing a PPRP. Central to this process is the concept of the control premium, or the right to make decisions when unanticipated events occur. The optimal assignment of control rights will vary by PPRP and is a function of the type of good produced by the partnership. Finally, in Chapter 11 we offer summary remarks and present practical suggestions to universities interested in forming a PPRP. 


\section{NOTES}

1. These data include funding data from the "business sector, federal government, nonfederal government, universities and colleges, and other nonprofit organizations" (NSF, 2013).

2. For the purpose of clarity, in this book we use the term "public-private partnership (PPP)" to refer to any partnership between a public entity and a private firm. When a partnership specifically focuses on research and development, we use the designation "public-private research partnership (PPRP)." 